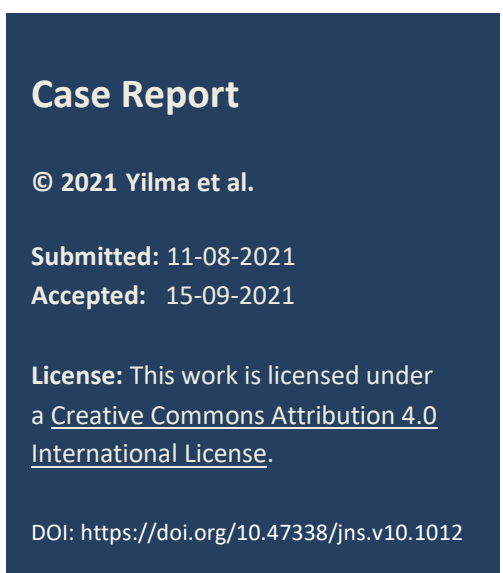

\section{A case of prenatally diagnosed prune belly syndrome variant and congenital pouch colon in the United States: A case report}

\author{
Mignote Yilma, ${ }^{1}$ Karen Trang, ${ }^{1}$ Marisa Schwab, ${ }^{1}$ Max Bowman, ${ }^{3}$ Mark Sugi, ${ }^{2}$ Jesse Courtier, ${ }^{2}$ Laurence S. Baskin, ${ }^{3}$ \\ Doruk Ozgediz, ${ }^{*}$ \\ 1 Department of Surgery, University of California San Francisco, CA, USA \\ 2 Department of Radiology and Biomedical Imaging, University of California San Francisco, CA, USA \\ 3 Department of Urology, University of California San Francisco, CA, USA
}

Correspondence*: Dr. Doruk Ozgediz MD MSc, Associated Professor of Surgery, Division of Pediatric Surgery, Director, Center for Global Surgery and Health Equity, University of California, San Francisco, 550 16th Street, Mission Hall 5th floor, San Francisco, CA 94143. E-mail: doruk.ozgediz@ucsf.edu

\section{KEYWORDS \\ Prune belly syndrome, Congenital pouch colon, Congenital colovesicular fistula, Anorectal malformation}

\begin{abstract}
Background: Prune belly syndrome (PBS) and congenital pouch colon (CPC) are rare congenital syndromes with a low incidence in the United States (U.S.) with most CPC cases being from India. In this case report, we describe, to the best of our knowledge, the first PBS variant and CPC patient in the U.S.

Case Presentation: A 30-year-old G2P0010 woman was referred to a tertiary center after an 18-week ultrasound showed a fetal abdominal mass. A prenatal MRI showed a dilated loop of bowel containing a mixture of urine and meconium, oligohydramnios, and a protuberant abdominal wall. Born at 37 weeks, the child's physical exam was notable for a distended abdomen with thin abdominal musculature, non-palpable bilateral testes, no anal opening, and flat buttocks. Intra-operatively, a dilated cecum/ascending colon was noted with an abrupt change in caliber at the transverse colon, bilateral enlarged ureters, a left testis at the internal ring and no visualized right testis. A colostomy and mucous fistula were created $5 \mathrm{~cm}$ from the sigmoid pouch.

Conclusion: While most reported cases of CPC undergo single stage repair (one operation) at 1 day of life, our patient underwent the first procedure of a staged repair at 16 hours of life given his clinical instability at the time as well as his unknown urological anatomy in the setting of urinary obstruction. This case demonstrates the importance of fetal imaging, multidisciplinary approach at a tertiary care center, and reinforces a staged repair when necessary.
\end{abstract}

\section{INTRODUCTION}

Prune belly syndrome (PBS) classically includes: hypoplastic/absent abdominal wall musculature; bilateral cryptorchidism; and urinary tract abnormalities (hydroureteronephrosis, megacystis, prostatic hypoplasia/dysplasia, renal dysplasia). In the U.S., the incidence of PBS is 3.8/100 000 live births, affecting majority males. [1] Anorectal malformations (ARM) have rarely been associated. PBS may result from an early error of embryogenesis, specifically of mesodermal development. [2] The definitive pathogenesis of PBS remains largely unknown.

Congenital pouch colon $(\mathrm{CPC})$ is a pouch-like dilation of varying amount of shortened colon, associated with ARM.[3] The pouch typically contains a fistula to the genitourinary tract. Like PBS, CPC has a strong male predominance (male to female ratio 2.25-7:1).[4, 5]
Over $90 \%$ of patient series of CPC and ARM are from India. [3] Patients with PBS and CPC have been described in a handful of case reports. Herein we describe a prenatally diagnosed patient with PBS and CPC, and the first patient in the U.S (to the best of our knowledge). We also performed a literature review of published cases to understand surgical outcomes for patients with this rare combination.

\section{CASE REPORT}

A 30-year-old G2P0010 woman was referred for evaluation due to an 18-week ultrasound concerning fetal abdominal mass. The mother's ancestry is Danish while the father's is English/Irish/German, with no family history of congenital anomalies. A fetal MRI revealed penile urethra dilation, protrusion of the abdominal wall suggestive of abdominal wall deficiency, right pelviectasis and dilated bowel containing heterogeneous signal intensity (Fig. 1). 

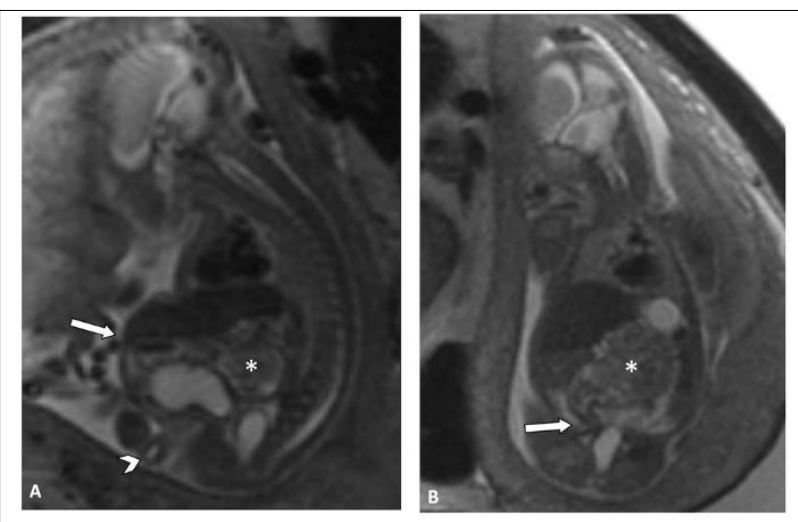

Figure 1: Congenital pouch colon, megalourethra, and prune belly syndrome on fetal MRI (3T) in a 30-year-old woman at 20 weeks 1 day. A) Sagittal T2WI shows the protuberant abdomen characteristic of prune belly syndrome, dilated and fluid-filled penile urethra (arrowhead), and pouch colon $\left({ }^{*}\right)$. B) Coronal T2WI shows abrupt tapering of the pouch colon $\left(^{*}\right)$ at the level of the rectosigmoid junction (arrow). The patient was induced at 36 weeks and 5 days for fetal growth restriction and delivered vaginally without complication

The 32-week ultrasound showed a protuberant fetal abdomen with intraluminal echogenic material suspicious for partially calcified meconium, which can be observed in vesicoenteric fistula due to the admixture of urine with meconium. No normal-appearing perianal complex was identified. The parents were counseled about the multiple fetal anomalies and wished to continue the pregnancy. Given intrauterine growth restriction $(<3$ rd percentile) and multiple fetal anomalies, the mother was induced at 37 weeks and a healthy male (birth weight $2.385 \mathrm{~kg}$ ) was delivered vaginally. The neonate had thin abdominal wall musculature, an enlarged ventral penis, non-palpable bilateral testes, bifid-type scrotum, no anus, and flat buttocks. An abdominal x-ray showed an air-filled loop of bowel in the right quadrant and orogastric decompression was initiated. At day 1 of age, he developed worsening abdominal distension (Fig. 2) and underwent a laparotomy. Intraoperatively, he had a distended bladder and urethral obstruction requiring a suprapubic catheter. His colon was free-floating without retroperitoneal attachments. The cecum and ascending colon were dilated until an abrupt transition at the transverse colon, impacted with inspissated meconium (Fig. 3). The sigmoid was dilated and ended in a blind pouch with a fistula to the bladder posteriorly. The fistula was not divided, instead a sigmoid colotomy was created to evacuate the meconium and irrigate the colon. After ensuring that there was no colonic stricture, a colostomy and mucous fistula were created $5 \mathrm{~cm}$ proximal to the sigmoid pouch. While an ileostomy was considered, the small bowel only measured $125 \mathrm{~cm}$, consistent with $45 \%$ of expected for age.[6] An intra-abdominal left testis was at the internal ring, but the right testis was not visualized. Postoperatively, the patient recovered uneventfully, a vesicostomy was created two weeks later, and the child was discharged on full oral feeds, gaining weight. A cystourethrogram at 2 weeks of age revealed grade 5 left vesicoureteral reflux, an enlarged bladder, and a small prostatic urethra. An antegrade contrast study through the mucous fistula showed $5 \mathrm{~cm}$ between the distal opacified colon and expected anal location. Genetic work-up included a normal microarray and Malformations Panel (Invitae).
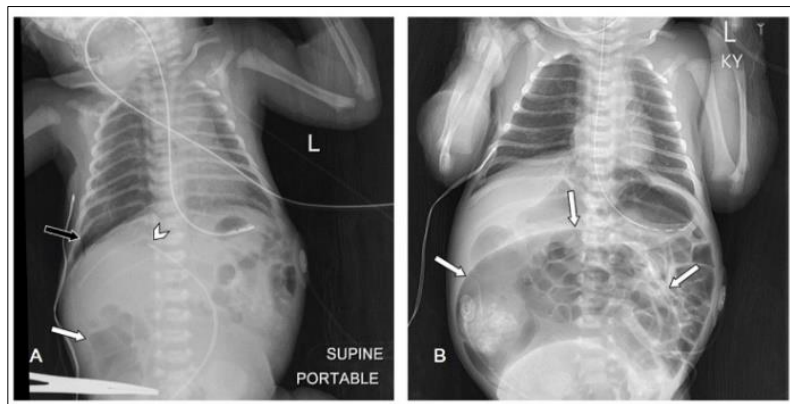

Figure 2: Chest and abdomen radiographs approximately 14 hours apart demonstrating rapid progression of bowel dilation. A) Day of life 0 radiograph shows a nonobstructive bowel gas pattern with mild distention of the right colon (white arrow). Note the malpositioned umbilical venous catheter-directed towards the right portal vein (arrowhead) and small right pneumothorax (black arrow). B) Day of life 1 radiograph shows massive gaseous dilation of the congenital sigmoid pouch colon (arrows).

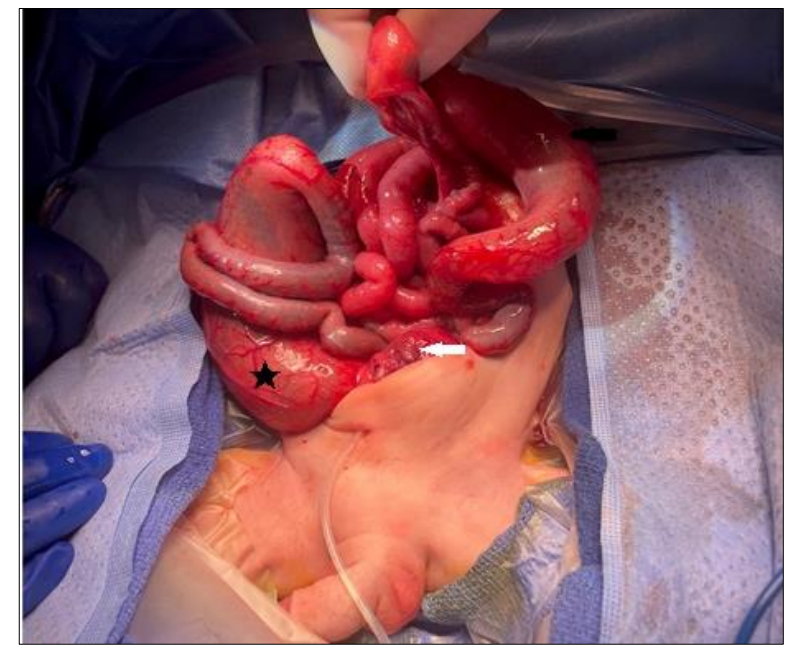

Figure 3: Intraoperative photo showing the dilated cecum and ascending colon (black arrow), with an abrupt change in caliber at the transverse colon. Pouch colon (black asterisk) and urinary bladder (white arrow) are also visible.

\section{DISCUSSION}

To our knowledge, this is the first report of a child prenatally diagnosed with PBS and CPC, and the first report from the U.S. (Table 1). Three patients received uneventful antenatal care; the remainder either had not received any prenatal care or it was not specified. Most patients presented on the first day of life. All but one patient underwent a single-stage repair (one operation rather than several) including fistula ligation, pouch excision, and creation of end colostomy or ileostomy. The patient in the earliest case report underwent staged colostomy followed by a pull-through. Our report describes the prenatal imaging, and surgical approach, and provides insights for future cases. 
Table 1: Literature review of patients with Prune belly syndrome and congenital pouch colon

\begin{tabular}{|c|c|c|c|c|c|c|c|}
\hline Author & Year & Country & Gender & Antenatal care & $\begin{array}{c}\text { Type of } \\
\text { pouch colon }\end{array}$ & Surgical management & Outcome \\
\hline Yadav et al.[10] & 1979 & Australia & M & $\begin{array}{l}\text { Uneventful } \\
\text { pregnancy }\end{array}$ & III & $\begin{array}{c}\text { Staged: first, colostomy, } \\
\text { second abdominoperineal } \\
\text { pull-through, }\end{array}$ & $\begin{array}{l}\text { Doing well at } 8 \text { month } \\
\text { follow-up }\end{array}$ \\
\hline $\begin{array}{l}\text { Bangroo et } \\
\text { al..[11] }\end{array}$ & 2005 & India & M & $\begin{array}{l}\text { Uneventful } \\
\text { pregnancy }\end{array}$ & I & $\begin{array}{l}\text { Ligation of fistula, pouch } \\
\text { excision, end ileostomy }\end{array}$ & $\begin{array}{c}\text { Uneventful } \\
\text { postoperative course }\end{array}$ \\
\hline Baba et al.[12] & 2010 & India & M & Not specified & IV & $\begin{array}{l}\text { Ligation of fistula, pouch } \\
\text { excision, end colostomy }\end{array}$ & $\begin{array}{l}\text { Doing well at } 2 \text { month } \\
\text { follow-up }\end{array}$ \\
\hline $\begin{array}{l}\text { Ragavan et } \\
\text { al.[13] }\end{array}$ & 2011 & India & M & Not specified & $?$ & $\begin{array}{l}\text { Ligation of fistula, pouch } \\
\text { colon converted into tube } \\
\text { and brought up as end } \\
\text { colostomy }\end{array}$ & $\begin{array}{c}\text { Uneventful } \\
\text { postoperative course }\end{array}$ \\
\hline $\begin{array}{l}\text { Annigeri et } \\
\text { al.[14] }\end{array}$ & 2013 & India & M & $\begin{array}{l}\text { No prenatal } \\
\text { care }\end{array}$ & IV & $\begin{array}{l}\text { Ligation of fistula, pouch } \\
\text { excision, end colostomy }\end{array}$ & $\begin{array}{c}\text { Uneventful } \\
\text { postoperative course }\end{array}$ \\
\hline Garge et al.[15] & 2015 & India & M & $\begin{array}{l}\text { Uneventful } \\
\text { pregnancy }\end{array}$ & IV & $\begin{array}{l}\text { Ligation of fistula, pouch } \\
\text { excision, end colostomy }\end{array}$ & $\begin{array}{c}\text { Sepsis from UTI, } \\
\text { death on } \\
\text { postoperative day } 5\end{array}$ \\
\hline Raj et al.[16] & 2017 & India & M & $\begin{array}{l}\text { No prenatal } \\
\text { care }\end{array}$ & V & $\begin{array}{l}\text { Ligation of fistula, pouch } \\
\text { excision, end colostomy }\end{array}$ & $\begin{array}{c}\text { Uneventful } \\
\text { postoperative course }\end{array}$ \\
\hline
\end{tabular}

Abbreviations: M, male; UTI, urinary tract infection

After fetal MRI, the differential diagnosis included congenital megalourethra, PBS, high ARM, and CPC with colovesicular fistula. A coordinated effort between the referring provider and tertiary care center facilitated multidisciplinary counseling including maternal-fetal specialists, nephrologists, pediatric surgeons, pediatric urologists, and neonatologists. The mother was induced with a multidisciplinary team on standby.

The optimal surgical approach for $\mathrm{CPC}$ is controversial. In isolated $\mathrm{CPC}$, several strategies are described, with two or more staged procedures with or without pouch excision or protective colostomy. [7-9] Our patient was stable at birth, with radiographic findings typical of CPC; thus, the decision was made for initial orogastric decompression and fluid resuscitation. However, the patient developed rapidly worsening abdominal distention with imaging concerning intraabdominal air, necessitating emergent surgery. Patients with PBS and CPC who have the benefit of a prenatal diagnosis may require early (within 12 hours of life) operative exploration.

Several aspects of our operative approach are relevant. A left-sided "hockey stick" incision with ligation of the colovesicular fistula has been described. [8] We performed a transverse infraumbilical incision due to significant abdominal distension and hypoplastic abdominal wall. Dilation of the cecum/ascending colon and presence of a rectosigmoid pouch was initially consistent with CPC type V. However, thick inspissated meconium was found obstructing the transverse colon, and after removal, the cecal distention improved leading to a diagnosis of CPC type IV with a single rectosigmoid pouch. Ligation of the colovesicular fistula was considered. However, without a full understanding of the urologic anatomy in the setting of urinary obstruction, we were concerned that ligation would increase the risk for urinary leak. Additionally, we worried that early pouch excision may limit future reconstructive options. Thus, a colostomy and mucus fistula were performed, and the pouch colon was preserved. The appendix was preserved to allow for potential appendicostomy for antegrade flushes or Mitrofanoff for bladder catheterization. Given the multitude of his anomalies, the current plan is for a three-stage repair with the next stage being fistula ligation and pull-through at approximately one year of life.

The patient exhibited many of the urology anomalies seen in PBS such as enlarged bladder with bilateral hydroureteronephrosis. Difficulty placing a urethral catheter was likely due to hypoplasia of the prostatic urethra or penile abnormalities. Intraoperatively, the testicles were intra-abdominal, however had descended bilaterally by 4 weeks. Vesicoureteral reflux may require reimplantation of ureter, which can be done simultaneously or as a staged approach with the management of the neurogenic bladder.

This report is the first to demonstrate that PBS and CPC can occur in North America in fetuses of European ethnic descent. While other cases likely exist, they may have been considered typical high ARMs. The objective of this report is to improve the knowledge and recognition of PBS and CPC to allow for better surgical collaboration in the care of these patients. We recommend early referral to fetal treatment center and fetal MRI for early diagnosis, which may facilitate rapid operative intervention. Early coordination with a multidisciplinary team is critical for patients with this complex combination of congenital syndromes.

\section{Acknowledgements: Nil \\ Conflict of Interest: None}

Source of Support: Nil

Consent to Publication: Author(s) declared taking informed written consent for the publication of clinical photographs/material (if any 
used), from the legal guardian of the patient with an understanding that every effort will be made to conceal the identity of the patient, however it cannot be guaranteed.

\section{REFERENCES}

1. Routh JC, Huang L, Retik AB, Nelson CP. Contemporary epidemiology and characterization of newborn males with prune belly syndrome. Urol. 2010; 76:44-8.

2. Walker J, Prokurat AI, Irving IM. Prune belly syndrome associated with exomphalos and anorectal agenesis. J Pediatr Surg. 1987; 22:215-7.

3. Chadha R. Congenital pouch colon associated with anorectal agenesis. Pediatr Surg Int. 2004; 20:393-401.

4. Angotti R, Salih Q, Molinaro F, Ferrara F, Sica M, Bindi $\mathrm{E}$, et al. Congenital pouch colon associated with anorectal malformation: A rare anomaly of Asian Region - experience of Kurdish centre. Afr J Pediatr Surg. 2018; 15:5.

5. Ghritlaharey R, Budhwani KS. Two-staged management for all types of congenital pouch colon. Afr J Pediatr Surg. 2013; 10:17-23.

6. Gondolesi G, Ramisch D, Padin J, Almau H, Sandi M, Schelotto PB, et al. What is the normal small bowel length in humans? first donor-based cohort analysis. Am J Transplant. 2012; 12:S49-54.

7. Singh S, Rawat JD, Kumar P. Congenital pouch colon: Our experience with coloplasty. Afr J Paediatr Surg. 2018; 15:16-21.

8. Mathur P, Saxena AK, Simlot A. Management of congenital pouch colon based on the Saxena-Mathur classification. J Pediatr Surg. 2009; 44:962-6.
Author Contributions: Author(s) declared to fulfil authorship criteria as devised by ICMJE and approved the final version.

9. Ghritlaharey RK, Budhwani KS. Two-staged management for all types of congenital pouch colon. Afr J Paediatr Surg. 2013; 10:17-23.

10. Yadav K. Short colon associated with the prune belly syndrome. Int Surg. 1979; 64:83-5.

11. Bangroo AK, Tiwari S, Khetri R, Sahni M. Congenital pouch colon with prune belly syndrome and megalourethra. Pediatr Surg Int. 2005; 21:474-7.

12. Baba AA, Hussain SA, Shera AH, Patnaik R. Prune belly syndrome with pouch colon and absent dermatome. Afr J Paediatr Surg. 2010; 7:25-7.

13. Ragavan M HU, Pradeep PV, Sarvavinothini J. Rare association of prune belly syndrome with pouch colon. Pediatric Health, Medicine and Therapeutics. 2011; 2:912.

14. Annigeri VM, Bhat MT, Hegde HV, Annigeri RV, Halgeri AB. Prune belly syndrome with congenital pouch colon. J Indian Assoc Pediatr Surg. 2013; 18:79-80.

15. Garge S, Bawa M, Rao KL . Prune belly syndrome with pouch colon with scaphoid megalourethra: a newer embryological and prognostic perspective. Ann Pediatr Surg. 2015; 11:42-5.

16. Raj P, Birua H. Type V pouch colon, prune belly syndrome, and congenital anterior urethrocutaneous fistula. J Neonatal Surg. 2017; 6:38. 